\title{
Clinical learning environment in government and private hospitals in relation to gender in Karachi, Pakistan - a comparative study
}

\author{
Sharmeen Amin, Zafeer Ahmed Yazdani, Ghazala Usman \\ Jinnah Sind Medical University, formerly Sind Medical College, Dow University of Health Sciences, Karachi, Pakistan
}

Received: March 31, 2014

Accepted: July 13, 2014

Online Published: January 26, 2015

DOI: $10.5430 /$ jha.v4n2p9

URL: http://dx.doi.org/10.5430/jha.v4n2p9

\begin{abstract}
Introduction: Background: The Medical Education has two most essential basis, sound theoretical knowledge and proficient clinical skills. Both of these factors depend on an efficient method of teaching in a proper clinical set-up. So that the medical students get most of the benefit out of it by learning and developing their clinical skills. Objective: The main objectives of this study are to determine the presence of difference in the learning environment in government and private hospitals of Karachi and to determine whether there is any biasness present in these systems on the basis of gender of students.

Methods: Four renowned university hospitals were selected: two private and two government-based. 150 samples were collected from each university by a self-administered questionnaire. The analysis has been performed using SPSS 20 and the results are presented using chi square.

Results: The study established that there is a striking difference between the learning environment in these clinical set-ups based on the theoretical knowledge of the students, the proper schedule of classes, hands on experience gained in the ward, new knowledge gained at the end of a wards rotation, doctors' interaction with the students and the students' motivation. This was represented by the $\chi^{2}=10.173$ and $p \leq .00001 . M_{G}=5.73$ with a $S D=1.815$ while $M_{P}=6.76$ with a $S D=1.883(\mathrm{M}=$ mean, $\mathrm{G}=$ Government hospital environment, $\mathrm{P}=$ Private hospital environment). According to the study there is no difference in treatment of the students on the basis of gender represented by the $\chi^{2}=3.168$ and a $p$ is between .05 and .1 .

Conclusions: The private hospitals provide a sound theoretical knowledge to the students they lack the provision of optimum opportunities for the students to develop their clinical skills in comparison with government hospitals. It is however recommendable that both the systems lack any biasedness among the students on the basis of gender .
\end{abstract}

Key Words: Gender, Government hospitals, Hospital environment, Learning environment, Medical students, Private hospitals

\section{Introduction}

In this era, teaching hospitals are a basic necessity of all the medical colleges since they provide a clinical ground for the medical students to grow. ${ }^{[1]}$ They provide to the students a learning environment which is a multiple of the educational climate and the symbiosis of the degrees of imparting and attaining knowledge and its application. ${ }^{[2]}$ An educational climate, in itself, is the product of, first and foremost, the curricula, the students and teachers' interests, the academic backdrop and self and social perceptions; these are the established five scales of Medical Education Environment Measures. ${ }^{[3]}$ For a medical student, this environment is staged in a hospital set up, where he is acclimatized to

\footnotetext{
*Correspondence: Sharmeen Amin; Email: sharmeenamin26@gmail.com; Address: 408, A1, Billy’s Garden, Ab-ul Hassan Isphahani Road, Karachi, Pakistan.
} 
different facets of skills, such as history taking, clinical examination and reasoning, decision making, ethics and professionalism. The efficient imparting of the said skills requires a well structured curriculum and a supervisor willing to put it in affect. It is also important to note that he himself has to have sound knowledge, skills and the capacity to encourage a problem solving attitude with an astute deliberation of clinical practice. ${ }^{[4,5]}$ Accreditation council for graduate medical education (ACGME) evaluates a medical practitioner according to the following skill set- his medical knowledge, the ability to learn, and hence improve, via practice of skills, patient care, communication skills and methods of dealing with inter-personal relations and systembased practice. ${ }^{6]}$ The significance of a good learning environment can be assessed by the fact that it directly affects the professional outcome of the undergraduate medical students and many have been compelled to abandon their studies due to insufficient skill development. ${ }^{[3]}$

The students' attitude and methods of learning and comprehension are equally as important. ${ }^{[2]}$ Recent studies are indicative of progressive distress in the apprentices of medicine and surgery, which has shown to affect their capacity to learn and grow as medical practitioners; the outcome of the said psychopathological phenomenon charges academic performance as one of the more prominent culprits, hence putting all the more stress on the establishment of a sufficient medical educational climate. ${ }^{[5,7]}$ It is important to note that the relationship between a proficient skill provider and learner is that of the yin-yang; the two keep each other balanced while providing adequate academic replenishment, hence it is worth noting that concepts translate well into competence. ${ }^{[5]}$

The definition of a good learning environment also includes a wholesome set of work ethics; the ability to teach compassion and attain mutual respect is equally as important as any physical skill set. Students mistreated suffer traumatic de-idealization while, the behavior elicits a domino effect, taking down multiple generations of doctors into the realm of cynicism and poor behavioral practices, even getting in the way of patient-doctor relationships. ${ }^{[8,9]}$

There is also the battle of the gender; studies in Nepal and Nigeria show that most female students seem to be less pleased with the hospital learning environments, ${ }^{[3]}$ while studies in India have proved that they are usually more inclined to falter academically as compared to male students. $^{[3]}$

Although most medical institutions in Asia are government based, the past decade has seen an effluence of private medical institutions, with India leading the playing field. ${ }^{[10]}$ However, it would seem that Pakistan is not far behind with more than half the total number of medical schools being private. The trend has indeed made an effort to support the doctor-to-patient ratio, however a need for comparison and contrast arises when the question for improvement in clinical practices is brought forth. ${ }^{[10]}$

Taking all of the aforementioned factors into consideration, this study aims to determine the extent of cognition and skill development in medical students by a government medical set up in comparison to a private establishment, the factors in a clinical learning environment in each set up that motivate learning and skill development among students and the possibility of unique influences of the clinical learning environment on the male and female students in each set up.

\section{Methods}

The study is a cross sectional study. Students studying in the 3rd, 4th and final year of their medical education were included in the study and students studying in 1st or 2nd year of MBBS or those who have graduated from their respective medical schools were excluded from the study. The data was collected using a self-administered questionnaire from the students who met the inclusion criteria. The questionnaire was designed on a way making it students' centered, taking into account their perceptions about their teaching hospitals.

The data was collected from four renowned teaching hospitals of Karachi, Pakistan affiliated with four major universities in this city. The hospitals included two government based hospitals, namely Jinnah Post-Graduate Medical Centre affiliated with Jinnah Sind Medical University and Civil Hospital Karachi affiliated with Dow Medical College, and two private hospitals, namely Liaquat National Medical Centre affiliated with Liaquate National Medical College and Jinnah Medical College Hospital affiliated with Jinnah Medical and Dental College.

A permission to carry out the study was obtained from the in-charge of each hospital. A total of 600 samples were collected which included 150 samples from each hospital from the students who consented to participate in the study. The confidentiality of the students was maintained by assigning a study number to each of the samples.

The data was analyzed using SPSS 20. The teaching environment in private and government hospitals were compared using chi square test. The prevalence of discrimination in relation of gender in both the settings was also compared using chi square test.

\section{Results}

While it is necessary for both, the government and private, educational systems to have such an environment in which the students could develop their clinical skills to the most, according to this study the results for the comparison between these systems have the $\chi^{2}=10.173$ and $p \leq .0000$ indicating a remarkable difference between the learning environment of these systems. $M_{G}=5.73$ with a $S D=1.815$ 
while $M_{P}=6.76$ with a $S D=1.883\left(\mathrm{M}=\right.$ mean, $\mathrm{G}=\mathrm{Gov}-\quad$ The results came out to be a $\chi^{2}=3.168, p$ is between .05 ernment hospital environment, $\mathrm{P}=$ Private hospital environment). The parameters compared have been mentioned in detail in Table 1.

The study also determined the effect of the hospital working and .1 indicating that the clinical learning and working environment in these hospitals is not biased according to gender. The parameters compared have been mentioned in detail in Table 2.

environment on the students based on difference in gender.

The results are further presented in the figures 1 through 4.

Table 1: Comparison between government and private teaching hospitals on the following parameters

\begin{tabular}{llll}
\hline Parameter Compared & Chi Square & Degree of Freedom & P-Value \\
\hline Students' command on the theoretical background & 58.065 & 2 & $<.00001$ \\
learning environment in hospital & 10.173 & 2 & $<.00001$ \\
Hospital environment according to students & 82.249 & 3 & $<.00001$ \\
Schedule of classes in wards & 212.362 & 3 & $<.00001$ \\
Students'-doctor interaction & 48.08 & 3 & $<.00001$ \\
Doctor's motivation to the students & 48.361 & 3 & $<.00001$ \\
Doctor's cooperation with the students & 50.580 & 3 & $<.00001$ \\
Hands on experience gained in the wards & 38.186 & 3 & $<.00001$ \\
Lack of interest in attending the wards & 40.481 & 3 & $<.00001$ \\
Doctor's knowledge about their subject & 34.420 & 3 & $<.00001$ \\
Students think they have gained new knowledge at the end of the day & 56.525 & 3 & $<.00001$ \\
Students are motivated to participate in clinical work and skills & 349.041 & 3 & $<.00001$ \\
Grading of hospital environment according to students & 75.021 & 10 & $<.00001$ \\
Grading of teaching skills of doctors according to students & 30.264 & 10 & $<.00001$ \\
Grading of students satisfaction of what they learn in ward rotations & 51.043 & 10 & \\
\hline
\end{tabular}

Table 2: Comparison between male and female students on the following parameters

\begin{tabular}{llll}
\hline Parameter Compared & Chi Square & Degree of Freedom & P-Value \\
\hline Students' command on the theoretical background & 3.427 & 3 & .330 \\
Hospital learning environment according to students & 4.287 & 3 & .232 \\
Schedule of classes in wards & 7.501 & 3 & .057 \\
Student-doctor interaction & 3.533 & 3 & .316 \\
Doctor's motivation to the students & 5.932 & 3 & .114 \\
Doctor's cooperation with the students & 4.604 & 3 & .203 \\
Hands on experience gained in the ward & 3.689 & 3 & .297 \\
Lack of interest in attending ward rotations & 7.275 & 3 & .063 \\
Doctor's knowledge about their subject & 5.860 & 3 & .121 \\
Students think they have gained new knowledge at the end of the day & 4.936 & 3 & .176 \\
Students are motivated to participate in clinical work and skills & 7.294 & 3 & .064 \\
Grading of hospital environment according to students & 9.456 & 10 & .489 \\
Grading of teaching skills of doctors according to students & 7.703 & 10 & .657 \\
Grading of students satisfaction of what they learn in wards & 10.183 & 10 & .424 \\
\hline
\end{tabular}

\section{Discussion}

In any teaching hospital throughout the world the prime important factor after patient care is the teaching provided to the students and how effectively they learn from it. ${ }^{[11]}$ The educational environment of a medical school has a signifi-

Published by Sciedu Press cant impact on the learning and academic well being of the students. ${ }^{[12]}$ The study intends to provide a looking glass for each medical training program, namely: private and government hospital institutions and hence, hopes to help improve the learning environment of the medical undergraduates and 
to address the issues in each system that hinder the growth of the said students as effective medical practitioners.

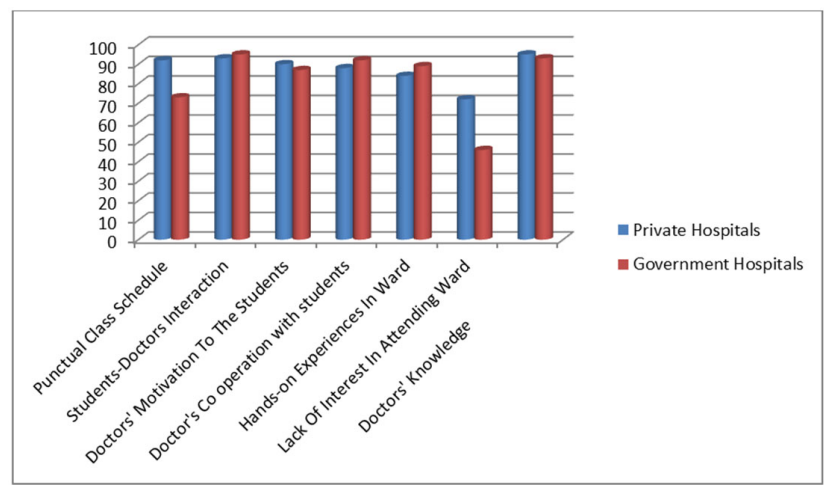

Figure 1: Illustrates the difference in frequencies of the following parameters in government and private hospital settings (with frequency on the $\mathrm{y}$-axis and parameters on $\mathrm{X}$-axis)
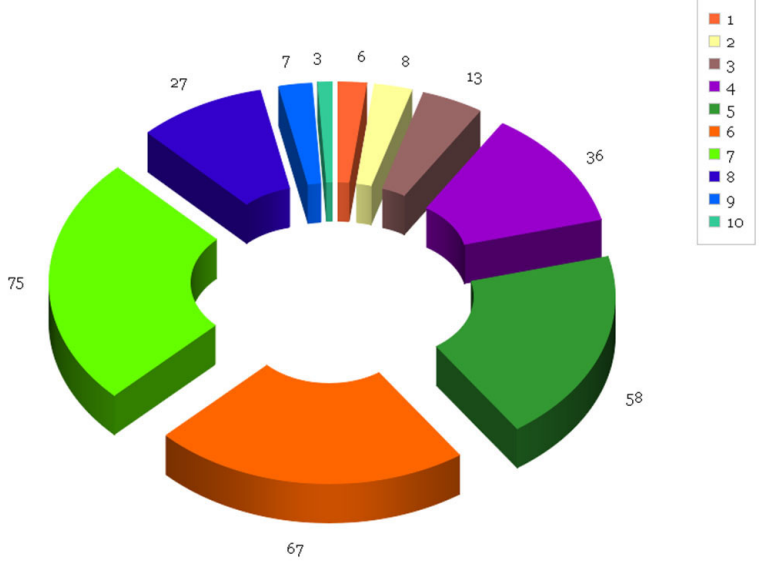

Figure 2: Illustrates the grading of hospital environment in government hospitals according to students (the numbers shown along the slices indicate the number of students and the colors indicated in the boxes represent the grade given by the students out of 10)

Any learning environment is constituent on three factors which include: the doctors setting up the examples about the hospital working conditions for the students, the students' perceptions about the learning environment and the expectations they have for their future as doctors in light of their perceptions. ${ }^{[13]}$ With the basis of an effective learning environment established, this study embarks on a journey to bring-forth and hence evaluate the strengths and inadequacies of each system, the causes for such differences and their repercussions on the undergraduates. For a more thorough understanding of the extent of application of each of the facets of the learning environment in either system, the results have been discussed according to the aims of the study.

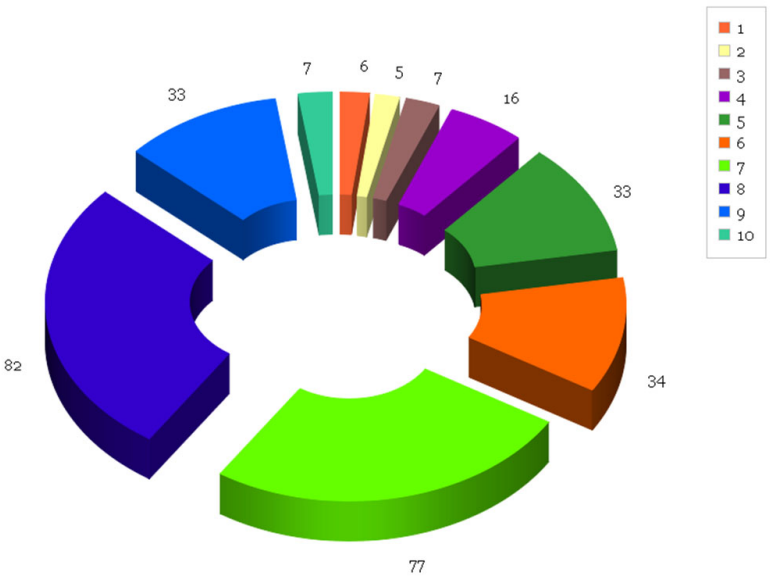

Figure 3: Illustrates the grading of hospital environment in privcate hospitals according to students (the numbers shown along the slices indicate the number of students and the colors indicated in the boxes represent the grade given by the students out of 10 )

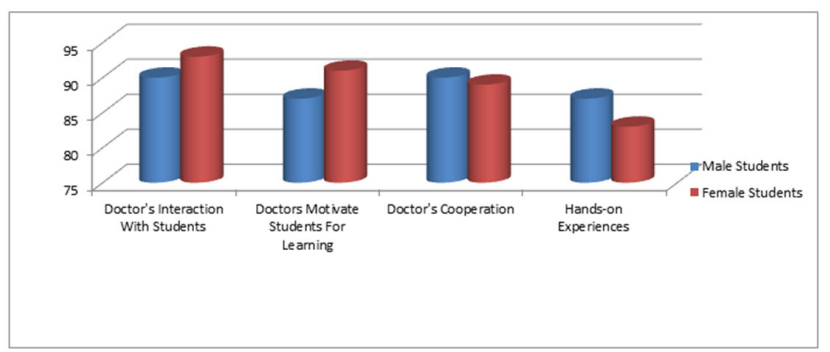

Figure 4: Illustrating the opinions of males and females students about some important parameters in both the hospital settings (with frequency on the y-axis and parameters on $\mathrm{x}$-axis)

The aforementioned facet is fashioned by the joint efforts of punctuality of the classes and teachers, participation and interaction between the doctors and the students, possession of sound skills and knowledge by the teaching staff alongwith the ability to impart such expertise.

An efficient teacher is crucial to the circle of learning and practice; he not only imparts knowledge but in return reinforces his own thereby improving his own skill-set. Hence, he not only helps establish the basis of proficient doctors but adds his name to the list as well. The word "doctor" comes from a Latin word "docere" which means "to teach". [14] A doctor spends most of his life as either a student or a teacher. ${ }^{[15]}$ Keeping all of this in mind, our results indicate that $72 \%$ of students from private institutes agreed that their classes were scheduled on time, while an effective $46.3 \%$ of students from government institutes claimed that classes were sometimes on schedule and only $15 \%$ students said that the classes are regularly scheduled on time. 
The relationship of doctors with the students holds extreme importance since it is the doctors who can effect the aims of their students by setting up remarkable examples for them. ${ }^{[16]}$ When asked about the teacher-student relationship, $65.3 \%$ of students from private based institutes said that the doctors interacted with the students and $51.7 \%$ claimed that they were cooperative. Considering the same factors in government institutes, it was shown that $47.4 \%$ of the students agreed to have an interaction with the doctors however only $34.3 \%$ of the total students surveyed from the latter institutes, claimed that they had a healthy, cooperative relationships with their teaching doctors.

The students were also questioned about the frequency of attaining new knowledge during classes; $56 \%$ of students from private institutes claimed that they felt like they have had, in fact, learned something new at the end of each class while only $34.7 \%$ of government institute students claimed as such, $44.7 \%$ gleaned new knowledge sometimes. Investigating these statistics further, the students were asked about the extent of knowledge possessed by the teaching doctors and whether they encouraged student participation; it was found that $71.7 \%$ of students from private institutions agreed that the doctors were proficient and knowledgeable $54.7 \%$ encouraged participation. While $51.3 \%$ government institute based students agreed the doctors were knowledgeable, only $34.3 \%$ claimed that they encouraged participation all the time.

The hospitals should provide such an atmosphere in which the student not only learn new clinical skills but get attached to the hospital setting and working environment as a good doctor should love the environment they work in which is a mark of professionalism. ${ }^{[17]}$ this means that the students should be provided with an environment which keeps the students' interest up. However, when asked about losing interest in the wards, a surprising twist came forth; $53.8 \%$ of government-based institute students denied loss of interest in the wards, while only $28 \%$ of private institute students seemed to agree with their government counterparts. Given the conceptual teaching methods and cooperative teachers, the results for the lack of interest in wards seem quite paradoxical. The results factor down to one clinical component: hands-on skills. About $41 \%$ of private institute students, in comparison to $44.7 \%$ government institute students have hands-on skills. These statistics throw a lime light on the importance of learning practical skills.

The transition period for a student from just a theory learner to a student who spends time on clinical rotations has been proven to be a very stressful period for the students because initially they are unable to apply the knowledge they have to a clinical setting. ${ }^{[18,19]}$ This stress can be decreased by the inclination to learn and practice on individual basis, the incentive of a wholesome hospital environment and an inspiring teacher. ${ }^{[20]}$ While the curriculum establishes the shape of the learning environment, however its adequacy and effi-

Published by Sciedu Press ciency is only instituted by proficient supervisors and teachers. ${ }^{[12]}$ Undergraduates derive their motivation by experiencing doctor-patient relationships and being challenged by a cataclysmic mentor. ${ }^{[15,21]}$ According to a study conducted in 2005, students learn better with bedside teaching methods as compared to any other means of learning. ${ }^{[16]}$

The skills the students learn as undergraduates provide the building block for the soundness of their clinical skills all through their lives. ${ }^{[2]}$ When asked about the hospital environment, $53.7 \%$ of private institute students claimed that the hospital environment was up to the standard, while $20.3 \%$ government institute students agreed with their private counterparts, $40 \%$ believe it is not up to the standard.

Students were also asked about being inspired by their teachers; $53.9 \%$ of students from private institutes found the doctors motivating however only $39.3 \%$ of students from government-based institutes were inspired by their teachers.

An ideal clinical environment should hold same grounds of ooprtunities for both the genders. Keeping this in mind it is essential to draw the attention towards the prevalence of discrimination among the medical students on the basis of gender. This is very common in the clinical settings of USA, ${ }^{[23]}$ UK, ${ }^{[24]}$ Nigeria, ${ }^{[9]}$ Sweden $^{[25]}$ and Asia. ${ }^{[3]}$

To date, the women constitute greater than $50 \%$ of the medical students in United States. ${ }^{[2]}$ According to a study conducted in Nigeria, $33.8 \%$ of all the female medical students experienced some act of mistreatment personally which is a very high percentage compared to their male colleagues. ${ }^{[9]}$

The effects of this sexual discrimination include severe depression, decreased self confidence, lack of interest in attending the ward and even dropping out from medical schoo. ${ }^{[19,26]}$ This also effects the female medical students' clinical performance and their preference for specialities later in life. ${ }^{[24]}$

It is therefore nothing less than a blessing that there is complete absence of any discrimination in relation of gender in the clinical set-ups of these private and government hospitals. This provides equal chances for the clinical growth and development of both the genders which is very beneficial for the society at large.

\section{Conclusion}

Given the results of the study, each system has their own critical failings and hence requires unique solutions. While the private hospitals provide a sound theoretical basis to the students, they lack the practical skills to certain extents. However lacking in the theoretical basis, government hospitals have nevertheless, helped their students to harness the clinical skills. It is however, established that an effective and proficient medical practitioner is a prodigy of both, strong theoretical medical knowledge and excellent hands- 
on skills.

A discrimination among the students on the basis of gender can lead to development of disinterest towards the field. It is therefore, a positive factor in both in systems that they are free from this discrimination and provide both the genders an equal chance to grow and develop themselves in the field of medicine.

\section{References}

[1] Al-Muhanna F A. The future of academic medical centers in Saudia Arabia: Difficulties encountered in a teaching hospital. J Family Community Med. 1999 Jul; 6(2): 23-8.

[2] Al Rukban M O, Khalil M S, Al-Zalabani A. Learning environment in medical schools adopting different educational strategies. Educ RecRev. 2010; 5(3): 126-129.

[3] Mayya S S, Roff S. Students' perceptions of medical environment: A comparison of academic achievers and under-achievers at Kasturba Medical College, India. Education for health. 2004; 17: 280291. PMid: 15848815 . http://dx.doi.org/10.1080/1357628 0400002445

[4] Al Kadri H M F, Al-Moamary M S, Elzubair M, Magzoub M E, Al Mutairi A, Roberts C, et al. Exploring factors effecting undergraduate medical students' study strategies in the clinical years: a qualitative study. Adv in Health Sci Educ. 2011; 16: 553-567. PMid: 21207243. http://dx.doi.org/10.1007/s10459-010 $-9271-2$

[5] Busari J O, Scherpbier A J J A. Why residents should teach: A literature review. J Post Grad Med. 2004; 50(3): 205. PMid: 15377808

[6] Fang J T, Ko Y S, Chien C C, Yu K H. Assessing medical students' performance in core competancies using multiple admission programs for college and universities: from the perspective of multisource feedback. Biomed J. 2013; 36(4): 188-197. PMid: 23989314 http://dx.doi.org/10.4103/2319-4170.113856

[7] Shah M, Hassan S, Malik S, Sreeramareddy CT. Perceived Stress, Sources and Severity of Stress among medical undergraduates in a Pakistani Medical School. BMC Med Educ. 2010; 10(1): 2. PMid: 20078853. http://dx.doi.org/10.1186/1472-6920-10-2

[8] Fayez R, Nawwab A, Al-Jhadali H, Baharoon S, Binsalih S, Al Sayyari A. Negative ethical behaviors in Saudi hospitals: How prevalent are they perceived to be?- Statement agreement study. Avicenna J Med. 2013; 3(3): 57-62. PMid: 24251232. http://dx.doi .org $/ 10.4103 / 2231-0770.118458$

[9] Owoaje E T, Uchendu O C, Ige O K. Experiences of mistreatment among medical students in a university in South West Nigeria. Nigerian J Clin Prac. 2012; 15(2): 214-219. PMid: 22718176. http://dx.doi.org/10.4103/1119-3077.97321

[10] Shehnaz S I. Privatization of medical edication in Asia. Southeast Asian J Med Educ. 2011; 5(2): 18-25.

[11] Al-Rubaish A M, Rahim S I A, Hassan A, Ali A A, Mokabel F, Hegazy M, et al. Developing questionnaires for students' evaluation of individual faculty's teaching skills: a Saudi Arabian pilot study. J Fam Community Med. 2010; 17(2): 91. PMid: 21359032 http://dx.doi.org/10.4103/1319-1683.71991

[12] Shehnaz S I, Sreedharam J, Gomathi K G. Faculty and Students' Perceptions of Student Experiences in a Medical School Undergoing Curricular Transition in the United Arab Emirates. Sultan Qaboos Univ Med J. 2012; 12(1): 77-85. PMid: 22375262. http: $/ /$ dx.doi.org/10.12816/0003091

[13] Bauer J, Groneberg D A. Perception of stress-related working conditions in hospitals (iCept-study): a comparison between physicians and medical students. J Occup Med Toxicol. 2013; 8: 3. PMid: 23442606. http://dx.doi.org/10.1186/1745-6673-8-3
[14] Mole G, Gillespie L. Those who can, teach. Assessing medical students' perception of a finals revision programme delivered by foundation and core trainees: a cross-sectional study. BMJ Open. 2012; 2(6).

[15] Elnicki D M, Cooper A. Medical Students' Perceptions of the Elements of Effective Inpatient Teaching by Attending Physicians and Housestaff. J Gen Intern Med. 2005; 20(7): 635-639. http: //dx.doi.org/10.1007/s11606-005-0109-1

[16] Brasher A E, Chowdhry S, Hange L S, Prinz R A. Medical Students' Perceptions of Resident Teaching. Ann Surg. 2005; 242(4): 548-555. PMid: 16192815 .

[17] Swick H M, Szenas P, Danoff D, Whitcomb M E. Teaching Professionalism in Undergraduate Medical Education. J Am Med Assoc. 1999; 282(9): 830-832. http://dx.doi.org/10.1001/jama.28 2.9 .830

[18] Godefrooij M B, Diemers A D, Scherpbier A J J A. Students' perceptions about the transition to the clinical phase of a medical curriculum with preclinical patient contacts: a focus group study. BMC Med Educ. 2010; 10(1): 28. PMid: 20367885. http://dx.doi.o $\mathrm{rg} / 10.1186 / 1472-6920-10-28$

[19] Stebbing J, Powles T. Stress in the workplace amongst medical professionals. J Postgrad Med. 2007; 53(2): 83-84. http://dx. doi .o $\mathrm{rg} / 10.4103 / 0022-3859.32202$

[20] Spencer J A, Jordan R K. Learner centred approaches in medical education. BMJ. 1999; 318(7193): 1280-1283. http://dx.doi.org $/ 10.1136 / \mathrm{bmj} .318 .7193 .1280$

[21] Fluit C R M G, Boulhuis S, Grol R, Lean R, Wensing M. Assessing the Quality of Clinical Teachers. J Gem Intern Med. 2010. 25(12):1337-1345. PMid: 20703952. http://dx.doi.org/10. 1007/s11606-010-1458-y

[22] Jolly B C, Macdonald M M. Education for practice: the role of practical experience in undergraduate and general clinical training. Med Educ. 1989; 23(2): 189-195. http://dx.doi.org/10.1111/j.1 365-2923.1989.tb00885.x

[23] Stratton T D, Mclanghin M A, Witte F M, Fosson S E, Nora L, Margaret M D. Does Students' Exposure to Gender Discrimination and Sexual Harassment in Medical School Affect Specialty Choice and Residency Program Selection? Acad Med. 2005; 80(4): 400408. PMid: 15793027. http://dx.doi.org/10.1097/0000188 8-200504000-00020

[24] Diderichsen S, Johanson E E, Verdonk P, Lagro-Jansen T, Hamberg $\mathrm{K}$. Few gender differences in specialty preferences and motivational factors: a cross-sectional Swedish study on last-year medical students. BMC Med Educ. 2013; 13(1): 39. PMid: 23497262. http://dx.doi.org/10.1186/1472-6920-13-39

[25] Hamberg K, Johanson E E. Medical students' attitudes to gender issues in the role and career of physicians: a qualitative study conducted in Sweden. Med Tech. 2006; 28(7): 635-641. PMid: 17594556. http://dx.doi.org/10.1080/01421590600 871007

[26] Babaria P, Bernheim S, Nunez-Smith M. Gender and the pre-clinical experiences of female medical students: a taxonomy. Med Educ. 2011; 45(3): 249-260. PMid: 21299600. http://dx.doi.org/1 $0.1111 / j .1365-2923.2010 .03856 . x$ 